\title{
Estado, vivienda de interés social e inmobiliarias en México*
}

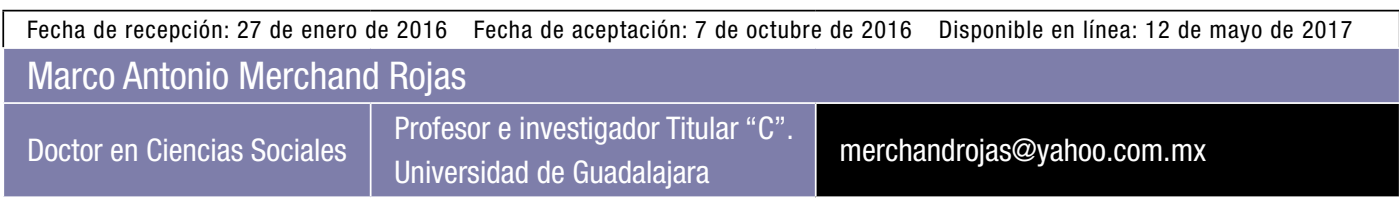

Resumen El objetivo de este ensayo es analizar cómo el Estado mexicano, desde inicio de la década del noventa hasta mediados de 2016, ha aplicado los fundamentos del modelo neoliberal mediante reformas en política de vivienda encaminadas a privatizar el suelo rural-urbano. Para llevar a cabo esta instrumentación, el Estado deja su papel activo-interventor en la construcción de vivienda de interés social y traspasa el compromiso a los promotores inmobiliarios y a la industria de la construcción ${ }^{1}$. En este artículo se utiliza el abordaje teórico y conceptual denominado modelo neoliberal para explicar las razones por las que el Estado instrumenta una política neoliberal ${ }^{2}$ en favor de los capitales inmobiliarios y hasta qué grado el Estado ha operado como intermediario, validando la coerción extraeconómica o expropiación - expulsión-y ocupación de suelos ${ }^{3}$ o espacios para asegurar la rentabilidad al capital inmobiliario. Se concluye que el efecto de dicho modelo neoliberal no se ha cumplido por parte de las inmobiliarias, pues no se han ofrecido casas que cumplan con los requisitos mínimos habitables (usan materiales de ínfima calidad y sus construcciones no sobrepasan los $60 \mathrm{~m}^{2}$ ). Además, la mayoría de estos conjuntos habitacionales carecen de centros comerciales, escuelas, centros culturales y lugares de esparcimiento, por lo que se convierten en grandes dormitorios aislados de la ciudad.

Palabras clave Estado; inmobiliarias; viviendas; social; exclusión

\footnotetext{
Artículo producto de investigación financiada por el Consejo Nacional de Ciencia y Tecnología. El proyecto se titula "Estado e inmobiliarias en México" y se desarrolló durante una estancia sabática en la Universidad de Tri, Roma.

1 En México se otorga connotación de vivienda de interés social a las viviendas construidas para trabajadores que cotizan en el Instituto Mexicano del Seguro Social (IMSSS) y que, acorde con sus ingresos, les corresponde una casa habitación. Las zonas de vivienda de interés social son los conjuntos habitacionales construidos por los organismos oficiales (Infonavit y Fovissste) y las zonas de vivienda popular son grandes extensiones alrededor de la ciudad (áreas periféricas)

2 Las políticas neoliberales se han presentado en dos fases: una de destrucción de las disposiciones institucionales vigentes mediante reformas orientadas al mercado; la otra se refiere a la creación de una nueva infraestructura y normatividad centradas en el capital (Nick, Peck y Brennerly, 2009). 3 El suelo es un recurso estratégico sobre el cual se producen subdivisiones y servicios que lo definen como "tierra urbana". Es el soporte de las edificaciones en donde se desarrollan y se expanden las ciudades y también es un bien transferible en el mercado que permite obtener riqueza y poder.
}

Cómo citar este artículo: Merchand, M. (2017). Estado, vivienda de interés social e inmobiliarias en México. Cuadernos de Vivienda y Urbanismo, 10(19), 6-21. https://doi.org/10.11144/Javeriana.cvu10-19.evis 


\section{State, Social Interest Housing and Real Estate in Mexico}

Abstract The objective of this paper is to analyze how the Mexican State, from the beginning of the 1990s until the middle of 2016, has applied the bases of the neoliberal model by means of reforms in housing policies aimed at privatizing rural-urban lands. In order to carry out this implementation, the State abandons its active-controller role in the building of social interest housing and transfers this commitment to the real estate developers and the construction industry. This article uses the theoretical and conceptual approach called neoliberal model to explain the reasons why the State implements a neoliberal policy in favor of real estate capitals and to what extent the State has operated as an intermediary, based on extra-economic coercion or land/spaces expropriation -expulsion- and occupation to ensure the profitability of real estate capital. We conclude that the effect of this neoliberal model has not been fulfilled by real estate developers, since they have not offered houses that meet the minimum habitable requirements (they use very poor quality materials and their constructions do not exceed $60 \mathrm{~m}^{2}$ ). Additionally, most of these housing complexes lack shopping malls, schools, cultural centers, and entertainment venues, making them large dormitories, isolated from the city.

Keywords state; real state agencies; housing; social; exclusion

\section{Estado, habitação de interesse social e imobiliárias no México}

Resumo O objetivo desta comunicação é analisar como o Estado mexicano, desde inícios da década de noventa para meados de 2016, tem aplicado os alicerces do modelo neoliberal mediante reformas na política de habitação visando privatizar o solo rural-urbano. Para levar a cabo essa instrumentação, o Estado deixa o papel ativo-interventor na construçáo de habitação de interesse social e transpassa o compromisso aos desenvolvedores imobiliários e a indústria da construção . Neste artigo utiliza-se a abordagem teórica e conceitual nomeada modelo neoliberal para explicar as razoes pelas que o Estado instrumenta uma política neoliberal em favor dos capitais imobiliários e até qual grau o Estado tem operado como intermediário, usando a coerção extraeconômica ou expropriação - expulsãoe ocupação dos solos ou espaços para garantir rentabilidade para o capital imobiliário. Conclui-se que o efeito de tal modelo neoliberal náo foi cumprido por parte das imobiliárias, pois não foram oferecidas moradias que cumprissem com os requisitos mínimos habitáveis (usam materiais de ínfima qualidade e as construçóes não excedem os $60 \mathrm{~m}^{2}$ ). Além disso, a maioria destes complexos habitacionais carece de shoppings, escolas, centros culturais e locais de lazer, pelo que mudam para grandes dormitórios isolados da cidade. 


\section{Introducción}

Cuando inició el gobierno de Carlos Salinas de Gortari (1988-1994) se aplicó con mayor ortodoxia la política neoliberal, en atención a los procedimientos que dicta el Banco Mundial (BM): el Estado adopta un papel de formulador de políticas desreguladoras que permiten mayor intervención del sector privado y garantizan los derechos de propiedad, para conseguir el beneficio exclusivo del sector privado. Respecto a la política de vivienda instrumentada por el Estado, este tiene una inspiración promovida por el Banco Mundial, consistente en otorgar o facilitar condiciones idóneas para que el mercado inmobiliario viabilice financieramente sus proyectos habitacionales.

Con este discurso neoclásico o neoliberal de los organismos (FMI, BM), a mediados de la década del noventa, el Banco Mundial (1994) publicó el documento Vivienda: un entorno propicio para el mercado habitacional. En sus primeras páginas enuncia la evolución de la política de la vivienda del Banco Mundial durante la década de 1980 y comienzos de 1990 y propone varios cambios importantes de orientación de políticas tanto para el Banco como para sus prestatarios. Propugna por la reforma de las políticas, instituciones y normas gubernamentales para que los mercados inmobiliarios funcionen con eficiencia.

El argumento central del BM fue "aconsejar" a los Gobiernos que dejaran de lado su anterior función de interventores sobre la producción de vivienda y asumieran el papel de facilitadores y garantes de los derechos de propiedad libre. El BM sostiene que la mejor manera de apovechar la información acerca del funcionamiento de mercados es el uso de estrategias que limitaran la intervención del Estado para multiplicar los efectos de las actividades del sector privado. Es más, señala el BM que si se dejan funcionar los mercados inmobiliarios por sí solos, pueden hacer mucho mejor su tarea para sastifacer las necesidades de la vivienda. Como lo explica Claudia Puebla (2002), desde la década del ochenta, las políticas de vivienda se fueron transformando del enfoque de la "provisión"” al enfoque "facilitador".

El objetivo del BM y de la burocracia estatal consistía en allanar el camino a todo tipo de inversiones por medio de las privatizaciones de los activos públicos que legalmente están a su resguardo. Con el estilo de desarrollo neoliberal, se instrumenta la venta de estos activos (privatizaciones) y se empieza a operar una devaluación masiva de sus activos (reservas territoriales, por ejemplo).

Estas facilidades que otorga el Estado federal o local al capital inmobiliario para apropiarse de espacios y urbanizar apuntan a reiniciar un nuevo ciclo de capital a partir de la venta de los activos devaluados y así construir en áreas factibles de ser urbanizadas (conjuntos habitacionales); esto reproduce el capital y amplía el mercado de suelos urbanizables. No obstante, por más contradictorio que parezca, es la propia necesidad del capital inmobiliario por conquistar nuevos espacios lo que hace indispensable el papel Estado para resguardar dichas inversiones. 
Este ensayo se ordena en cinco apartados: 1) estado del arte y propuesta metodológica; 2) instituciones de Gobierno y política de vivienda; 3) rescate del Estado a las inmobiliarias de vivienda de interés social; 4) evaluación de las inmobiliarias a partir de encuestas de satisfacción, y 5) construcción de viviendas y segregación social (exclusión social).

\section{Estado del arte y propuesta metodológica}

Hasta ahora, los ensayos sobre el objeto de estudio propuesto han sido muy escasos. Se destacan los análisis de Puebla (2002), Torres (2006) y documentos oficiales (Cidac, reportes informativos de Infonavit y Fovissste) que han sido descriptivos y poco analíticos. Este ensayo aporta un tratamiento original en cuanto a su abordaje y tratamiento metodológico.

El proceso heurístico que se propone inicia con la teorización del concepto de acumulación por despojo o desposesión, que cobra fuerza ideológica a partir del modelo neoliberal y representa, si no la única forma, sí la más importante para sostener o incrementar la acumulación de capital en las ciudades (Harvey, 2007; 2014;
De Angelis, 2012; Bonefeld, 2012; Composto, 2012). El rasgo económico-político que definiría dicha acumulación por despojo es que, para llevarse a cabo, precisa que el Estado y los dueños de capital (financiero-inmobiliario) tengan el interés común en que los espacios receptores (construcción de oficinas, centros comerciales, zonas habitacionales, casas de interés social, etc.) sirvan para que el capital se incremente, por medio de procesos de construcción en zonas habitacionales de interés social, sobre todo en las zonas periféricas.

La hipótesis que sustenta este ensayo consiste en proponer que la acumulación por despojo es orientada por el Estado en favor de los capitales inmobiliarios y se aplica como un principio homologado (por igual) en todas las economías del orbe, sean desarrolladas o en desarrollo. Uno de los elementos que ha cobrado importancia en este tipo de acumulación inicia con el apoyo irrestricto del Estado 5 para salvaguardar los intereses del capital financiero-inmobiliario (por ejemplo, en la crisis financiera inmobiliaria de Estados Unidos y España y en la crisis económica de México $)^{6}$.

Sin embargo, las condiciones en las que el capital financiero inmobiliario ${ }^{7}$ se impone en cada espacio urbano difieren en sus métodos y maneras

\footnotetext{
5 Una línea que marcó al filósofo Henri Lefebvre (1978) fue la presencia del Estado como organizador y articulador del espacio, para calificar de cierta forma el espacio definido por la racionalidad de la expansión del capitalismo y la intervención del Estado por medio de la planificación y el ordenamiento del territorio.

6 La crisis de 2008 en Estados Unidos mostró cómo operó el Estado de manera invariable en favor del sistema financiero inmobiliario y contribuyó a una apropiación y acumulación privada de riqueza, sustentadas en prácticas depredadoras de sistemática defraudación bancaria. Utilizó pirámides Ponzi, manipulación de los tipos de interés y demás artificios de la ingeniería financiera. La búsqueda de rentas inmobiliarias se logró arrebatando la riqueza de otros, cuyo origen consistió en crear un mercado de vivienda diseñado para extraer al prestatario todo el dinero posible y someterlo a todo tipo de comisiones y primas ilimitadas por parte de las inmobiliarias. A esto se le llama acumulación por despojo pues, al final, además de su vivienda, el prestatario pierde sus ahorros y su empleo por una economía en clara recesión. En el caso español, el capital bancario, financiero e inmobiliario domina y trastoca la vida de millones de personas que han sido afectadas directa 0 indirectamente en sus condiciones de vida material y espiritual y los despoja de sus casas o de sus empleos. Por supuesto, el Estado español también protegió sin cuartel a la banca y a las inmobiliarias que especularon con los precios del suelo y de las casas, sin importar que todavía contaran con el apoyo irrestricto del Estado para legitimar judicialmente los desahucios de miles de españoles. En México, las inmobiliarias establecen nexos o alianzas político-económicas con el Estado federal y local para aprovechar suelos de las periferias metropolitanas para edificar zonas habitacionales de "interés social". El rescate financiero del Estado mexicano a las inmobiliarias es muy similar al que ocurre en otros países en condiciones similares: se privatizan beneficios y se socializan pérdidas.

7 "El capital inmobiliario puede ser, entonces, capital industrial (capital-productivo) bajo la forma mercancía producida materialmente por la industria de la construcción. Puede ser capital rentista bajo la forma de propiedad del inmueble o del suelo urbano mismo. 0 bien, puede ser capital financiero o bursátil inmobiliario en la medida que las inversiones de capital vayan destinadas a la inversión de portafolio en fondos financieros crediticios para la construcción de obra pública o privada, a la adquisición de bienes inmuebles (créditos hipotecarios), o al mercado bursátil a través de acciones de capital inmersos en la esfera de la construcción o de la propiedad inmobiliaria" (Capel, 2013, p. 221)
} 
de reproducirse; no obstante, su carácter intrínseco de enajenar o externalizar lo internalizado en beneficio de pocos se ha generalizado en la economía global y se aplica por igual en todas las ciudades.

La acumulación por despojo no puede implementarse sin el apoyo irrestricto del Estado. Este ha sido un actor central para privatizar y mercantilizar el espacio urbano. Por ser el Estado empleador de la violencia y hacedor de la legalidad, es evidente que todo proceso económico que implique manejo de recursos económicos o activos financieros pasa por su tamiz para cubrir jurídicamente el despojo, pues hay que recordar que el Estado es un poder de clase que se expresa en flexibilizar las leyes (desregulación) para que las denominaciones del capital se adueñen de ejercer el derecho a la ciudad de forma exclusiva.

Como se ha explicado, para facilitar las prerrogativas del BM en cuanto a otorgar todas las facilidades a los capitales inmobiliarios, el Estado mexicano modificó el Artículo 27 constitucio$\mathrm{nal}^{8}$ en 1992 , consistente en que ya se puede privatizar el ejido y las tierras comunales ${ }^{9}$, entrar al mercado de tierras y estar disponibles para que los capitales inmobiliarias compren suelo y construyan viviendas de interés social.

Lo cierto es que, después de la reforma al Artículo 27, se registra un acelerado e intensivo proceso de privatización y despojo de recursos considerados comunes (propiedad social y comunal) ${ }^{10}$. Los ejemplos sobre los casos de presión que se ejerce sobre el suelo pueden instrumentarse a partir de procesos de desconcentración industrial y poblacional de ciudades grandes y medias que extienden su mancha urbana sobre zonas periféricas ${ }^{11}$. Estas zonas son utilizadas como áreas habitacionales ${ }^{12} \mathrm{y}$ responden a la lógica de una expansión urbana $^{13}$ (Schteingart, 1979) ${ }^{14}$.

No se tiene espacio ni tiempo para enunciar ejemplos sobre cómo la reforma al Artículo 27 constitucional ha desencadenado un proceso duradero de acumulación por desposesión.

Respecto a la justificación de este texto, es necesario en mostrar cómo el Estado mexicano solventa la crisis inmobiliaria rescatando con sumas millonarias a las principales inmobiliarias de México en 2010, aunque estas siguen endeudándose con los bancos. Algunas de ellas

8 "Con la reforma al artículo 27 constitucional se propició el cambio en el panorama para las periferias urbanas. Este cambio, se dio gracias a que por primera vez resultaba legal y técnicamente favorable contar con suelo susceptible de urbanizar. El gobierno ve en las reformas constitucionales el reconocimiento del proceso de urbanización y del derecho de los ejidatarios a decidir de manera individual lo que quisieran hacer con sus tierras; de cambiar el uso de estas, incorporarlas al mercado y aprovechar su plusvalía). Se termina la posición tutora del Estado sobre las comunidades campesinas — que ahora deberán valerse en un ambiente de libre competencia—, el gobierno se deslinda de estos sectores de la sociedad y es el mercado el encargado de establecer la arena para las transacciones de los ejidatarios en esta nueva realidad" (Warman, 1996, p. 18)

9 "Los propietarios originales (ejidatarios, comuneros, pequeños propietarios, etcétera) pueden vender la tierra a promotores inmobiliarios que se encargarán de valorizar la tierra introduciéndola en los procesos de capital. Así, los terrenos periféricos de las ciudades se transforman en un objeto mercantil, dinamizando un mercado que acelera y consolida la urbanización capitalista. El proceso que inicia con la compra del terreno controlada por los promotores inmobiliarios, sigue con la incorporación de valor, por medio del trabajo de los ocupantes, y culmina con la aparición de los aparatos del Estado para regularizar la tierra" (Legorreta, 1991, p. 7).

10 "La Procuraduría Agraria (PA) y el Registro Agrario Nacional —en adelante, RAN— dan asesorías para la desincorporación de suelo social para el desarrollo urbano. Estas orientan a los sujetos agrarios para que, de acuerdo con la legislación vigente, sea desincorporada la tierra social para el desarrollo urbano, a través de los procedimientos de adopción del dominio pleno sobre parcelas o la aportación de tierras de uso común para la constitución de inmobiliarias, en el mejor de los casos, o venderlas a particulares, como sucedió en la mayoría de los asuntos, a favor de especuladores o grandes compañías constructoras, que obtenían las tierras a precios irrisorios para la edificación de complejos habitacionales, pues la mayor parte de las ciudades en México estaban próximas a terrenos ejidales" (Salinas, 2009).

11 Muchas de las zonas de la periferia metropolitana se han caracterizado por la ocupación del suelo en asentamientos irregulares.

12 La población de estas poblaciones periféricas se establece en ellas por un reducido valor del suelo y también porque no se encuentran muy distantes de las delegaciones centrales de la ciudad, en donde se concentra la mayor cantidad de empleo, educación, salud y centros culturales, entre otros.

13 El fenómeno de la periurbanización y del crecimiento de zonas conurbadas o metropolitanas ha significado nuevas configuraciones territoriales en las que la ciudad desborda sus límites territoriales o municipales a expensas del territorio de los municipios rurales circundantes (Paré, 2010).

14 Se destaca el estudio de Schteingart (1979), quien hace un balance de la incorporación de tierras rurales de propiedad social (ejidal y comunal principalmente) al área urbana de la ciudad de México durante el período de 1940 a 1980. Se revisa también el papel desempeñado por los promotores privados, las inmobiliarias y las instituciones de crédito a la incorporación de la tierra ejidal y comunal. 
fueron apoyadas y ahora se declaran en concurso mercantil, pero siguen incurriendo en apalancamiento o endeudamiento y afrontan denuncias de frentes ciudadanos por incumplir con la entrega satisfactoria de las viviendas construidas.

En relación con la construcción epistémica que sustenta este artículo, se empleó el enfoque crítico de la Economía Política como referente macro para explicar el accionar de los actores económicos y políticos (Estado e inmobiliarias en la escena del territorio). La línea argumentativa está trazada desde un escenario abstracto (modelo neoliberal) hasta llegar a un escenario concreto (Estado neoliberal federal y local). Esta postura dialéctica de ir de lo general a lo particular de ida y vuelta en forma de espiral muestra la solidez de las conjeturas.

\section{Instituciones de Gobierno y política de vivienda}

Con el modelo neoliberal a cuestas, el Gobierno federal instrumenta cambios en todos las instituciones de vivienda: 1) la banca fue desregulada y reprivatizada, incorporó nuevos programas habitacionales y constituyó una nueva oferta de financiamiento para los promotores privados; 2) los organismos dependientes del Estado se separan de la banca y buscan fuentes alternativas de recursos, como los provenientes del BM; 3 ) los fondos para vivienda (Instituto del Fondo Nacional de la vivienda para los trabajadores - Infonavity Fondo de la vivienda del instituto de seguridad y servicios sociales de los trabajadores al servicio del Estado -Fovissste-) transformaron su forma de operar (dejaron de ser los grandes productores de conjuntos habitacionales), cambiaron su sistema de promoción habitacional (abrieron las puertas a los promotores privados) e incrementaron la importancia de sus programas de crédito individual, y 4) el Infonavit disminuyó subsidios y atiende a solo cierto tipo de demanda (la que tiene alguna solvencia de acuerdo con los salarios ganados).

En México, el mercado habitacional por parte de las instituciones administrativas del Gobierno se compone de los siguientes oferentes: organismos nacionales de vivienda (fondos sobre aportaciones, entre los que destacan el Infonavit y el Fovissste); otras instituciones gubernamentales locales (organismos estatales de vivienda) y nacional (Fonhapo, entre otros), que otorgan créditos hipotecarios y subsidios a su población objetivo; la Sociedad Hipotecaria Federal (antes FOVI); instituciones financieras privadas (bancos mercantiles, Sofoles, etc.), con programas y políticas específicas de crédito hipotecario para el mercado de ingresos medios y altos (Torres, 2006).

En este ensayo solo se analiza el caso de Infonavit, que es el instituto más representativo en cuanto al número de agremiados que aportan un porcentaje de su salario a partir de las contribuciones que hacen las empresas (patrones). La reforma a la política de vivienda consistió en limitar el papel del Gobierno federal y de las instituciones de vivienda, las cuales tendrían que transitar de ser constructoras a ser solo promotoras para la construcción de viviendas de interés social, en otras palabras, a tener la única función de facilitar el otorgamiento de créditos y así permitir su acceso. $\mathrm{Al} \mathrm{mismo} \mathrm{tiempo,}$ el sector privado se consideraba más eficiente para afrontar el desafío habitacional y se convertía en el actor principal en la construcción de vivienda social.

Los años de 1989 a 1994 se distinguieron por una tendencia hacia la desregulación del sector habitacional que permitió una mayor intervención de los agentes privados financieros, promotores y constructores, en un contexto de 
injerencia de los principales organismos internacionales como el Banco Mundial, que promovió las llamadas estrategias facilitadoras.

Con base en Leal (2012) y otros autores estudiosos del tema como García (2010) y Boils (2004), se puede sostener que la vivienda social en México nunca ha recibido recursos suficientes, pues incluso algunos de los principales dineros han provenido del ahorro de los trabajadores mediante la aportación de su salario que hacen los patrones. Por ello, desde 1987, el Infonavit abandonó su papel de promotor de vivienda, de acuerdo con los lineamientos del Banco Mundial que le impone condiciones con base en los préstamos que le otorgó durante la década del noventa. Uno de los requisitos del BM es que los créditos a la vivienda otorgados sean rentables. El Infonavit quedó únicamente como gestor administrativo de la vivienda de interés social y el sector privado (inmobiliarias) se hizo responsable de la producción de vivienda de interés social en México.

La exigencia del Banco Mundial hacia el Infonavit ${ }^{15}$ es que establezca una "adecuada política habitacional" y que sea rentable, por lo que los intereses cobrados no deben ser menores a las tasas de inflación; esto convierte al Infonavit en un negocio. Entonces, la propuesta del BM es que el Infonavit pierda su objetivo de fondo solidario.

El análisis de la política de vivienda desde 1990 permite ver a las instituciones públicas de la vivienda en México como algo cercano a una función comercial, pues solo debe otorgar créditos a las familias que ganen más de cinco salarios mínimos y que estén inscritas en el sector formal del trabajo. De esa forma, el Infonavit ya no representa un fondo solidario de vivienda social.

\section{Rescate del Estado a las inmobiliarias de vivienda de interés social}

El mercado mexicano registra 1.200 compañías constructoras de viviendas, según datos de la Comisión Nacional de Vivienda (Conavi). La mayoría de las constructoras e inmobiliarias participa en proyectos residenciales de escala relativamente pequeña, de cincuenta a quinientas casas. Solo un pequeño segmento construye más de 10.000 casas (Mancera SC, 2011).

Las inmobiliarias de México resienten la crisis financiera inmobiliaria de 2008 iniciada en Estados Unidos. Sus manifestaciones se hacen patentes en marzo de 2009. Con el objetivo de evitar el colapso del sector inmobiliario mexicano, el expresidente Felipe Calderón puso en marcha su primer intento de rescate por medio del Pacto Nacional por la Vivienda, mediante el cual fueron otorgados 60.150 millones de pesos. Un año más tarde se entregaron 16.000 millones de pesos más. El rescate se encaminó a mantener estables los indicadores de las seis empresas inmobiliarias más grandes que cotizan en bolsa (“Crisis hipotecaria”, 2013).

Sin embargo, todavía en 2013 las seis inmobiliarias (Homex, Urbi, Geo, ARA, Sare y Ruba) afrontaban deudas bancarias por el equivalente a 2.294 millones de dólares. De ellas, Homex es la que tiene mayores pasivos bancarios, con $786 \mathrm{mi}$ llones de dólares. El Cuadro 1 muestra la deuda de las principales inmobiliarias con los bancos (González, 2013). El reporte de Ignacio Beteta (2012) indica que la cotización de las acciones de estas empresas durante 2010 y los primeros cinco meses de 2011 (18 mayo de 2011) muestran una minusvalía que contrasta con un rendimiento 
positivo de $10,1 \%$ del índice de precios y cotizaciones (IPC). El índice que agrupa el resultado de las acciones de las seis empresas arroja una variación negativa de $-24,7 \%$. En el período señalado, las acciones con menor minusvalía son las de Geo, seguidas por las de Urbi.

Como se muestra en el Cuadro 1, los cinco principales bancos acreedores del sector son los que tienen en sus balances la mayor deuda contratada por inmobiliarias. El banco que registra el mayor número de pasivos en este sector es Banamex, por el equivalente a 370 millones de dólares (unos 4.600 millones de pesos), seguido por HSBC y Banorte, que dieron créditos a esta industria por 256 y 251 millones de dólares, de acuerdo con los datos de Standard and Poor's ${ }^{16}$. El diagnóstico de la firma calificadora Standard and Poor's ${ }^{17}$ consideró que la situación financiera de este grupo de inmobiliarias se agravó y que desde 2008 se desplomó la demanda de nuevas casas (González, 2013).

Mientras las deudas de las inmobiliarias crecen, cien mil viviendas fueron abandonadas por quienes en los últimos años compraron casa o departamento en los complejos habitacionales construidos en zonas alejadas de los centros urbanos (suelos ejidales y comunales). La acumulación de inventarios de las empresas desarrolladoras de viviendas y la falta de refinanciamiento por medio del sistema bancario derivaron en el colapso de sus operaciones y en incumplimiento de sus obligaciones financieras (González, 2013).

Lo anterior se confirma con una entrevista realizada en el periódico La Jornada. Antonio de Oca, consultor en finanzas y abogado mercantil (especialista en vivienda), expuso que en el cuarto mes de 2013 se inscribieron en el registro único

Cuadro 1.

Deuda bancaria de las principales inmobiliarias de vivienda 2013

\begin{tabular}{|c|c|c|c|c|c|c|c|}
\hline $\begin{array}{l}\text { Millones } \\
\text { de dólares }\end{array}$ & Homex & Urbi & Geo & Ara & Sare & Ruba & Total \\
\hline Banamex & 131 & 27 & 122 & 68 & 15 & 7 & 370 \\
\hline HSBC & 4 & 164 & 49 & - & 40 & - & 256 \\
\hline Banorte & 20 & 107 & 74 & 42 & 7 & 1 & 251 \\
\hline Banobras & 229 & - & 9 & - & - & - & 229 \\
\hline Inbursa & 211 & - & 254 & - & - & - & 219 \\
\hline $\begin{array}{l}\text { Total de los prin- } \\
\text { cipales bancos }\end{array}$ & 594 & 297 & 177 & 110 & 62 & 8 & 1.325 \\
\hline Otros & 191 & 337 & & 125 & 65 & 4 & 890 \\
\hline Total & 786 & 634 & 431 & 235 & 127 & 12 & 2.224 \\
\hline
\end{tabular}

Fuente: González (2013)

16 Standard \& Poor's (S\&P) es una agencia de calificación de riesgo, división de la empresa McGraw-Hill, dedicada a la elaboración y publicación periódica de calificación de riesgos de acciones y bonos. Es señalada por otorgar la categoría mayor AAA a grandes porciones de los paquetes de hipotecas basura, conocidos como collateralized debt obligation (CDO).

17 Según un estudio de Standard and Poor's, las inmobiliarias "crecieron a partir de la adquisición de reservas territoriales alejadas de las áreas urbanas que utilizaban como garantía para créditos puente. Las unidades habitacionales crecían separadas de las grandes ciudades bajo el supuesto de que la expansión urbana llegaría a esos desarrollos" (González, 2013). 
de vivienda (RUV) 18.099 casas, mientras en el mismo período de 2012 fueron 30.699 (Méndez, 2013a). Explicó que la baja en construcción de vivienda se debe a que está cerrada la llave del crédito a las inmobiliarias y añadió que las seis principales inmobiliarias que cotizan en la Bolsa Mexicana de Valores (BMV) sobrevaluaron los precios de las viviendas para lograr un crecimiento permanente de sus ventas, mantener sus utilidades y el precio de sus acciones durante los gobiernos de Vicente Fox y Felipe Calderón (2000-2012).

Existen tres inmobiliarias (Geo, Urbi y Homex) que en 2013 tuvieron vencimientos de deuda por más de 3.000 millones de dólares, según datos de la Bolsa Mexicana de Valores (BMV) y enfrentaron demandas de más de diez bancos, tanto en Estados Unidos como en México ("Pequeñas viviendas", 2013).

Los bancos en México mantienen una fuerte relación con el Gobierno para respaldar y financiar al sector hipotecario en México (Crisi y Enciso, 2014). Con este rescate por parte del Estado mexicano a las agencias inmobiliarias opera la acumulación por despojo, ya que es una transferencia de activos públicos a empresas inmobiliarias. Esta transferencia de activos es pagada por la población con sus impuestos y es la expresión de externalizar pérdidas y privatizar los beneficios.

\section{Evaluación de las inmobiliarias a partir de encuestas de satisfacción}

¿Cómo son evaluadas estas inmobiliarias? Los programas institucionales han creado encuestas de satisfacción residencial, que hace la Sociedad Hipotecaria Federal (SFH) anualmente desde
2006 y tiene como objetivos conocer el grado de satisfacción de la población que habita en dieciséis conjuntos habitacionales, en cuanto a la vivienda y la calidad de vida de su entorno (Cidoc y SHF, 2014).

La escala del índice de satisfacción residencial (ISR) tiene una base cuantitativa que utiliza una distribución normal de los resultados ponderados. Las calificaciones van del ISR 5 (la más baja) al ISR 10 (la mejor calificada).

El índice de satisfacción con la vivienda (ISV) es el promedio ponderado de las calificaciones y características físicas, espaciales y funcionales de la construcción, adaptaciones y transformaciones y características ambientales. En 2013 se ubicó en $6+$, es decir, poco satisfactorio. Todos los componentes del ISV presentaron una menor calificación con respecto al año 2012; sobresale la calificación de los componentes Características físicas de la construcción y Características ambientales, que disminuyeron dos grados.

En el Cuadro 2 se exhiben algunas inmobiliarias que cuentan con la menor calificación. Nótese que son los propios residentes quienes califican la situación de su vivienda.

Si al ISV se le agrega el trabajo de Sánchez Corral (2012), quien entrevista a personalidades del medio y que presentan alguna relación con el tema de la vivienda social en México, se confirma el bajo grado de satisfacción que reportan las inmobiliarias. Destaca el diálogo con el arquitecto Carlos Gonzáles Lobo ${ }^{18}$ :

¿Qué es la vivienda social? Respuesta: Es un horror. Yo creo que la vivienda no existe. Las empresas del mercado las producen en serie, pero lo que hacen son cajas. El tema de la vivienda es cómo albergar la actividad humana, cómo inscribirla en una configuración. La 
Cuadro 2.

Los diez conjuntos habitacionales peor evaluados

\begin{tabular}{|c|c|c|c|c|c|}
\hline Entidad & Municipio & Inmobiliaria & Conjunto & Índice & Tipología \\
\hline Durango & Gómez Palacio & Consorcio Ara & Cerrada Aranjuez & $5-$ & Económica \\
\hline Michoacán & Purepero Cre C & Inmobiliaria, SA de CV & Belén & $5-$ & Económica \\
\hline Michoacán & La Piedad & $\begin{array}{c}\text { Inmobiliaria y Constructora } \\
\text { Solórzano, SA de CV }\end{array}$ & Las Cañadas & $5-$ & Social \\
\hline Guerrero & Acapulco de Juárez & Corporación Geo & Villa Tulipanes & $5-$ & Social \\
\hline Quinta Roo & Othon P Blanca & Vivo desarrollo, SA & El Encanto 3 & $5-$ & Social \\
\hline Durango & Gómez Palacio & Corporación Geo & Cerrada Los Reyes & $5-$ & Social \\
\hline Querétaro & Querétaro & $\begin{array}{l}\text { Impulsora Residencial Qro., } \\
\text { SC de RL de CV }\end{array}$ & Milenio III & $5-$ & Social \\
\hline 0axaca & San Juan Bautista Tuxtepec & $\begin{array}{l}\text { Proyectos Inmobiliarios } \\
\text { de Culiacán, SA }\end{array}$ & Riveras del Atoyac & $5-$ & Social \\
\hline Michoacán & La Piedad & $\begin{array}{c}\text { Gestoría y Asignación } \\
\text { de Vivienda, SA }\end{array}$ & Residencial Cumbres & $5-$ & Económica \\
\hline Tabasco & Huimanguillo La Esperanza & $\begin{array}{c}\text { Grupo Inmobiliario y Comercial } \\
\text { Guía, SA de CV }\end{array}$ & La Esperanza & 5- & Social \\
\hline
\end{tabular}

Fuente: Cidoc y SHF (2014, p. 121)

vivienda es el albergue espacial de los hechos humanos habitables de cualquier tipo de familia. La vida es compleja y la vivienda debe ser poliforme. La casa es un objeto que no se puede definir y sin embargo ha sido codificado: sala, comedor, cocina, bańo y dos recámaras. Eso es lo que se ofrece en el mercado como casas y es objeto de crédito hipotecario. Son bastante malas, incluso criminales (p. 31).

\section{$\mathrm{Al}$ arquitecto Carlos García Vélez se le preguntó:}

¿Dónde está la vivienda social en la actualidad? Respuesta: La mía está muy mal. Hay mucho financiamiento. Se habla de números, pero no de calidad. Hay muy poca calidad. La vivienda social está muy lejos, muy monótona, muy mal comunicada y muy aislada. Por el mismo dinero que se hace una vivienda, si se hicieran planes maestros integrales bien hechos, y mezclándolos con diferentes promotores de todo tipo, haríamos maravillas (p. 14).
Estas evaluaciones negativas sobre el grado de satisfacción de las viviendas a las inmobiliarias (Homex, Geo y Urbi, Demet, Sare, Sadasi y un grupo de Sofoles) han ocasionado la apertura de averiguaciones previas en su contra. En la Procuraduría General de la República ${ }^{19}$, la averiguación se debe a la venta irregular de terrenos para licitar viviendas de interés social en el Estado de México.

El Frente Mexiquense en Defensa de una Vivienda Digna $(2015)^{20}$ presentó las denuncias penales correspondientes por el delito especial de fraccionadores o inmobiliarias que cometen fraude, lavado de dinero y delitos financieros como artificios normales para acrecentar sus ganancias (Méndez, 2013b).

La acusación sostiene que se aplicaron recursos públicos federales para la adquisición de terrenos en ros, contadores, arquitectos, economistas, maestros, doctores, obreros y trabajadores del sector servicios. Estas diversas expresiones se han unido con el fin de defender su patrimonio, combatir la impunidad y, mediante la lucha pacífica, resistir el poder corruptor de las inmobiliarias e hipotecarias, además de rechazar los lanzamientos o desalojos injustificados. Se conformó para denunciar y enfrentar a la economía de crimen inmobiliario e hipotecario en México, representada por las constructoras como Urbi, Sadasi, Homex, Geo, Ara, Sare, Promotora Integrales de Viviendas y las Sofoles como Patrimonio, Hipotecaria su casita, Ge Money, Infonavit, Fovissste y la Sociedad Hipotecaria Federal. 
zonas ejidales (acumulación por despojo) para la construcción y adquisición de viviendas con materiales y calidades de urbanización inferiores a las ofrecidas y además, que se adquirieron viviendas en conjuntos habitacionales que no cuentan con los servicios públicos que se ofertaron y se contrataron. Asimismo, la PGR acredita que entre 1999 y 2011, unos 10 millones de créditos hipotecarios fueron sobrevaluados hasta en un $40 \%$ en el país; no obstante, la PGR no ha solicitado órdenes de aprehensión ante el juez competente, porque aún no resuelve qué funcionarios y exservidores públicos fueron los probables responsables de los delitos de peculado, fraude genérico y específico, en colusión con empresarios de ese ramo.

Las empresas constructoras de vivienda de interés social ocupan el segundo lugar en cuanto a número de quejas presentadas ante la Procuraduría Federal del Consumidor (Profeco), solo después de las compañías de telecomunicaciones. El sector de la construcción siempre ha sido considerado por la autoridad como problemático frente al cumplimiento de la entrega de viviendas dignas a sus compradores. La Profeco tiene en su registro de 2009 más de 8.000 quejas en contra de unas 1.500 empresas del ramo, lo que ha llevado a la firma de acuerdos con Infonavit y Fovissste para obligar a las constructoras a registrar sus contratos ante la Profeco para que esta cuente con más elementos de apoyo a los consumidores.

En la lista de constructoras conflictivas se destaca la inmobiliaria Homex SA de CV, una de las más grandes por el número de viviendas construidas; sin embargo, se registran defectos estructurales, por lo que se presentan quejas continuas de quienes llegan a habitarlas. Durante el año 2009, la Profeco recibió 210 quejas contra esta empresa.

Tal vez todos estos factores y otros hacen que México tenga una de las tasas más altas de viviendas deshabitadas (14,2\%), acorde con datos de la OCDE. Supera incluso a las de aquellos países que recién han salido de una burbuja inmobiliaria, como Irlanda (13,8\%), España $(13,7 \%)$ y Portugal (12,5\%). Gran parte de las viviendas deshabitadas - una séptima porción del parque habitacional- se encuentra en las ciudades, aunque existe una variación considerable en su ubicación en las áreas metropolitanas (OCDE e Infonavit, 2015). De hecho, el problema de las viviendas deshabitadas en México parece ser más estructural que cíclico. Además, la ubicación de los nuevos desarrollos de vivienda, la migración y la inseguridad, han contribuido de forma importante a esta alta tasa de viviendas deshabitadas. A mediados de 2012, el propio Infonavit anunció que en su inventario de vivienda abandonada había más de 145.000 unidades y que alrededor de 45.000 casas serían subastadas a corto plazo (Ruiz, 2013).

Como lo sostiene el Centro de Investigación para el Desarrollo (Cidac, 1991), la vivienda en México es un problema prioritario desde cualquier punto de vista. En el tema vivienda se conjugan problemas políticos - personas y grupos que demandan, a veces con violencia, acceso a la vivienda-, problemas sociales - carencia de un lugar mínimamente apropiado para vivir y desarrollar hábitos de higiene y cultura- y problemas económicos -incapacidad de la mayor parte de la población de acceder al mercado de vivienda en virtud de los desequilibrios que causa una mala distribución del ingreso-.

Al Cidac le faltó algo por decir: la vivienda es producto de intereses contrapuestos, uno de ellos, el de los usuarios de vivienda que manifiestan sus reclamos porque la vivienda no cumple con las expectativas ofrecidas por las agencias inmobiliarias; de ahí que se formen frentes ciudadanos ${ }^{21}$ para exigir sus derechos. Los otros dos intereses 
(Estado e inmobiliarias), amañados y pactados, fingen que cumplieron con las normas de diseño de edificar vivienda digna. El Estado hace caso omiso de las reclamaciones o instruye para aplazar las respuestas judiciales que hay en contra de las inmobiliarias y de las instituciones de crédito, pues otorgar una sentencia favorable a los usuarios de vivienda es ir en contra de sí mismo.

\section{Construcción de viviendas y segregación social (exclusión social)}

Ahora bien, el negocio inmobiliario organiza la ciudad segregando las clases sociales con base en el precio de la vivienda. Los principales actores públicos y las entidades financieras que integran el sector hipotecario mexicano clasificaron los tipos de vivienda según su precio, cuya referencia y unidad de medida corresponde a "las veces de Salarios Mínimos Mensuales para el Distrito Federal"22 (Cidoc y SHF, 2012, p. 8).

La clasificación contempla seis tipos de vivienda: económica, popular y tradicional (agrupadas en la categoría de interés social), media, residencial y residencial plus. La vivienda de interés social es aquella que tiene un precio máximo de venta al público de quince salarios mínimos anuales vigentes en el distrito federal (Pina, 2013). Se considera que las viviendas de interés social son las económicas y populares, con un costo máximo de 350.000 pesos mexicanos. El Cuadro 3 refleja el tipo de vivienda según su precio.

La superficie es un factor clave de abaratamiento y por ello estas viviendas son reducidas en superficie en comparación con otras viviendas más caras (Cuadro 4).

\section{Cuadro 3.}

Clasificación homologada de las viviendas según tipo y precio

\begin{tabular}{ccc} 
Tipo de vivienda & $\begin{array}{c}\text { Vsmmdf (salario mínimo diario para el distrito } \\
\text { federal vigente a partir de enero de } 2010 \\
\text { de } 57,46 \text { pesos diarios) }\end{array}$ & $\begin{array}{c}\text { Rangos de precios en } \\
\text { pesos mexicanos* }\end{array}$ \\
\hline Económica & Hasta 118 salarios & 206.000 \\
\hline Popular & 118 a 220 salarios & 206.000 a 349.000 \\
\hline Tradicional & 220 a 350 salarios & 349.000 a 611.000 \\
\hline
\end{tabular}

Fuente: Cidoc y SHF (2012, p. 55)

Cuadro 4.

Características de los tipos de vivienda: costo, promedio de la superficie en $\mathrm{m}^{2}$ y del número de cuartos de la vivienda

\begin{tabular}{|cccc} 
Promedios de la & Económica & Popular & Tradicional \\
superficie en m $^{2}$ & 30 & 45 & 55 \\
\hline $\begin{array}{c}\text { Umbral máximo } \\
\text { costo (número de } \\
\text { salarios mínimos) }\end{array}$ & 118 & 220 & 350 \\
\hline $\begin{array}{c}\text { Número de cuar- } \\
\text { tos de la vivienda }\end{array}$ & $\begin{array}{c}\text { Baño, cocina, un habitable, } \\
\text { usos múltiples y 0,5 garaje }\end{array}$ & $\begin{array}{c}\text { Baño, cocina, un habitable, } \\
\text { usos múltiples y un garaje }\end{array}$ & $\begin{array}{c}\text { Baño, cocina, dos habitables, } \\
\text { usos múltiples y 0,5 garaje }\end{array}$ \\
\hline
\end{tabular}

Fuente: elaboración propia con base en Cidoc y SHF (2012, p. 55)

22 El salario mínimo diario para el distrito federal, vigente a partir del 1 de enero de 2010, es de 57,46 pesos, establecido por la Comisión Nacional de los Salarios Mínimos mediante resolución publicada en el Diario Oficial de la Federación del 23 de diciembre de 2009. Este salario mínimo diario se debe multiplicar por 30,4 para obtener la unidad de medida "veces salarios mínimos mensuales para el Distrito Federal" (VSMMDF): 1VSMMDF = 1.746,784 pesos mexicanos. 
Lo importante de los Cuadros 3 y 4 es la estimación sobre la capacidad de las unidades familiares para demandar cierto tipo de vivienda y esto se debe a la forma como está distribuida la riqueza. Además, hay que considerar los mecanismos de financiamiento disponibles para incorporar a aquellos grupos que no cuentan con los recursos suficientes para acceder a una vivienda digna. Estos factores determinan la demanda efectiva, que se refiere a la capacidad real que tiene un sector de la población para hacerse de una vivienda digna y que depende de la riqueza de la unidad familiar y su capacidad para acceder a los mecanismos de financiamiento disponibles.

En México, suele ocurrir que en aquellos sectores que no son capaces de demandar vivienda en forma efectiva, optan por aceptar espacios habitacionales que no cumplen con los requisitos mínimos de una vivienda digna. En general, se trata de los grupos que carecen de un ingreso suficiente y no cumplen con las condiciones para ser incorporados por los mecanismos financieros disponibles de acceso a la vivienda. Esta población no halla otra alternativa que invadir o comprar ilegalmente terrenos ejidales o comunales, ubicarse en tierras del Gobierno o en litigio o convertirse en víctimas de fraccionadores ilegales. Estas personas - que conforman la mayoría de la población- han autoconstruido su vivienda en condiciones muy precarias y son los que dan lugar principalmente a la demanda potencial.

Existe gente excluida de los programas institucionales de suelo urbanizado y de vivienda, que desarrolla procesos irregulares de poblamiento y autoproducción de su hábitat. La vivienda de autoconstrucción se define como aquella construida por el mismo habitante, sin algún factor político, legal o económico que lo respalde. Esta autoconstrucción y la falta de políticas públicas eficientes causan la generación de "viviendas informales", es decir, las que se construyen con materiales de calidad insuficiente, según los estándares del país.
El efecto sobre la pérdida de ingresos ha venido acentuando el deterioro de la calidad de vida $y$, por supuesto, en las condiciones de vivienda con las que se cuentan (OCDE, 2015).

Hay muchos estudios que analizan los índices de segregación residencial con datos censales y conteos poblacionales de área geoestadística básica (AGEB). Casi todos, si no es que todos, llegan a la conclusión de que la geografía de las metrópolis está estratificada de forma muy marcada por la posición socioeconómica de los hogares y las condiciones de la vivienda y, en menor medida, por los arreglos familiares y estructura por edad.

Hay que destacar el estudio de Sánchez Peña (2012), quien expone que la política habitacional actual diferencia la localización y el tipo de vivienda por estratos sociales. Esta visión de política contribuye a aumentar la segregación. Por supuesto que estas exclusiones, ya patológicas, de las grandes aglomeraciones urbanas conforman el paso de un patrón de asentamientos de alta densidad poblacional a uno de urbanización dispersa y más fragmentada.

El tipo de estructura territorial aludido conlleva espacialmente nuevas periferias y deriva en una dinámica de suburbanización o periurbanización que experimenta la mayoría de las ciudades de carácter metropolitano (Isunza y Méndez, 2011). El efecto espacial de esta estructura territorial desigual conduce a una concentración geográfica de los hogares pobres en zonas desfavorecidas de la ciudad y acarrea consecuencias sociales negativas: por un lado, favorece la reproducción intergeneracional de la pobreza y, por otro, la segregación se asocia con situaciones de riesgo social, emparentadas con el aumento de las tasas de delincuencia urbana (Cáceres y Sabatini, 2004).

Las inmobiliarias y la política habitacional aplicada por el Estado son los protagonistas que contribuyen a crear esos contrastes habitaciones desiguales 
(índices de segregación). Hay que recordar que es la misma lógica del capital la que se edifica a partir de crear desigualdades habitaciones, es decir, si el capital se expande según los ingresos distintos (ricos y pobres), entonces hay que construir aglomeraciones habitacionales para ricos (con todos los servicios comerciales y culturales) y otras para pobres (sin servicios culturales o educativos).

\section{Conclusiones}

Se expuso cómo se construyó el proceso epistémico (estrategia metodológica) que sustenta este ensayo, el cual fue construido a partir de inferencias de información sobre la crisis de 2008 en Estados Unidos y España. En ambos países, el Estado solventó el boom financiero hipotecario, así como su expresión de crisis económica y rescató a los que la habían provocado (banca e hipotecarias inmobiliarias) ${ }^{23}$.

Estos acontecimientos muestran cómo se propicia un contubernio indisociable entre los intereses del Estado, de la banca y de las inmobiliarias, desde el exponencial crecimiento de las finanzas de estas últimas hasta su declive (crisis). A partir de lo acontecido en Estados Unidos y España, se preguntó: si esto pasó en esos países, ¿por qué no pasaría en condiciones parecidas en México? Este "Estado capturado" por los intereses turbios de las finanzas e inmobiliarias indica la forma como se concreta la llamada acumulación por despojo, que es obtener beneficios adicionales a partir de préstamos depredadores en el mercado de la vivienda y consiste en transferir millones de dólares en activos del Gobierno a los financieros inmobiliarios (por medio de Infonavit y Fovissste, el Estado entrega recursos financieros a las inmobiliarias para que estas se encarguen de construir viviendas de interés social).

Se ha analizado que la producción masiva de vivienda de interés social a cargo de las inmobiliarias privadas se ubican en su mayoría en la periferia de la ciudades, pues aquí es en donde se pone en práctica la acumulación por despojo, al contar con superficies disponibles (ejidales y comunales) que permitan construir zonas habitacionales mediante la compra de terrenos o el recurso expropiatorio (declaración de utilidad pública) por parte del Estado.

Con lo revisado, se cree que ya se tienen mayores elementos para contestar los siguientes interrogantes. ¿Por qué los actores (Estado e inmobiliarias) hacen lo que hacen para conservar el statu quo de un sistema capitalista que cada vez muestra su naturaleza intrínseca de aumentar los beneficios para pocos (clase rentista bancaria e inmobiliaria, etc.) en detrimento de muchos (prestatarios de casas)?

El Estado brinda un entorno facilitador a las inmobiliarias, garantiza su reproducción de capital y permite maximizar su renta de suelo (al sobrevalorar los precios de la vivienda y especular sobre el uso del suelo); en cambio, al trabajador solo se le asegura sobrevivir en una casa de interés social pequeña y con falta de servicios educativos y culturales. Un Estado que no vela porque el trabajador cuente con vivienda digna fomenta una dinámica de exclusión socioespacial y refuerza un patrón de segregación social endémico. Existe un riesgo importante de que las viviendas de interés social se transformen en guetos urbanos, con problemas de deterioro material y social, seguridad, violencia y drogadicción. 


\section{Bibliografía}

“Crisis hipotecaria alcanza México. 76 mil 150 millones de rescate". (2013, julio 30). Revolución tres punto cero. Recuperado de http://revoluciontrespuntocero.com/crisis-hipotecaria-alcanza-mexico-76-mil-150-millones-de rescate/

"Pequeñas viviendas dispuestas a ganar mercado". (2013, abril 15). El Economista. Recuperado de http://eleconomista.com.mx/mercadosestadisticas/2013/04/15/pequenas-vivienderasdispuestas-ganar-mercado

Banco Mundial. (1994). Vivienda: un entorno propicio para el mercado habitacional. Recuperado de http://documentos.bancomundial.org/curated/es/878771468343734154/Vivienda-unentorno-propicio-para-el-mercado-habitacional

Beteta, I. (2012). Las desarrolladoras de vivienda en la bolsa mexicana de valores. Recuperado de http://www.ibeteta.com/LasDesarrolladoras deVivienda.asp

Boils, G. (2004). El Banco Mundial y la política de vivienda en México. Revista Mexicana de Sociologia, 66(2), 345-367.

Bonefeld, W. (2012). La permanencia de la acumulación primitiva: fetichismo de la mercancía y constitución social. Theomai (26). Recuperado de http://www.redalyc.org/articulo. oa?id=12426097011

Cáceres, G. y Sabatini, F. (eds.). (2004). Barrios cerrados en Santiago de Chile. Entre la exclusión y la integración residencial. Santiago: Lincoln Institute of Land Policy, Pontificia Universidad Católica de Chile.

Capel, H. (2013). La morfología de las ciudades III: agentes urbanos y mercado inmobiliario. En Ediciones del Serbal (editor de la serie), La Estrella Polar: núm. 62. Barcelona: Ediciones del Serbal.
Centro de Investigación para el Desarrollo [Cidac]. (1991). Vivienda y estabilidad politica. Reconcebir las politicas sociales. Ciudad de México: Diana, Autor.

Cidoc y SHF. (2012). Estado actual de la vivienda 2012. Ciudad de México: Autor.

Cidoc y SHF. (2014). Estado actual de la vivienda en México. Ciudad de México: Autor.

Composto, C. (2012). Acumulación por despojo y neoextractivismo en América Latina. Una reflexión crítica acerca del Estado y los movimientos socio-ambientales en el nuevo siglo. Astrolabio (8), 323-352.

Crisi, R. y Enciso, E. (2014, noviembre 28). Standard \& Poor's confirma calificaciones de "mxAAA" y "mxA-1+" de Sociedad Hipotecaria Federal. SorP Global Ratings. Recuperado de http://www.standardandpoors.com/ratings/ articles/es/la?articleType $=$ HTML\&assetID = 1245377993619

De Angelis, M. (2012). Marx y la acumulación primitiva. El carácter continuo de los "cercamientos" capitalistas. Theomai (26). Recuperado de http://revista-theomai.unq. edu.ar/NUMERO\%2026/De\%20Angelis\%20 - \%20 Marx\%20y\%20la\%20 acumulaci\% C3\%B3n\%20primitiva.pdf

Frente Mexiquense en Defensa de una Vivienda Digna. (2015). Comunicado. Quiénes somos. Recuperado de http://www.frentemex.org.mx/

García-Peralta, B. (2010). Vivienda social 19401999: actores públicos, económicos y sociales. Cuadernos de Vivienda y Urbanismo, 3(5), 31-42.

González, R. (2013, junio 16). Grandes inmobiliarias pasan por el peor momento de su historia. La Jornada. Recuperado de http://www.jornada. unam.mx/2013/06/16/economia/027n1eco

Harvey, D. (2007). Breve historia del neoliberalismo. Madrid: Akal. 
Harvey, D. (2014). Diecisiete contradicciones y el fin del capitalismo. (J. M. Mari Madariaga, trad.). Quito: Instituto de Altos Estudios Nacionales del Ecuador.

Isunza, G. y Méndez, B. (2011). Desarrollo inmobiliario y gobiernos locales en la periferia de la Ciudad de México. EURE, 37(111), 107-129.

Leal, J. (2012). La política de vivienda social en México desde la perspectiva funcional gubernamental. Innovaciones de Negocios. InnOvaciOnes de NegOciOs, 9(18), 341-365.

Lefebvre, H. (1978). El derecho a la ciudad. Barcelona: Península.

Legorreta, J. (1991). Rentas inmobiliarias y mercado del suelo en las periferias urbanas. Ciudades (1). Recuperado de http://www.rniu.buap.mx/ edit/revistas/contenido.php?id=1

Mancera SC. (2011). Análisis de la industria. Panorama general de la industria de la vivienda en México. Ciudad de México: Ernst \& Young.

Méndez, A. (2013a, mayo 6). Sector inmobiliario e hipotecario, en crisis desde hace dos décadas. La Jornada. Recuperado de http://www.jornada. unam.mx/2013/05/06/sociedad/041n1soc

Méndez, A. (2013b, noviembre 5). La PGR sabía del fraude en la venta de terrenos en el Edomex. La Jornada. Recuperado de http:// www.jornada.unam.mx/2013/10/14/index. php?section $=$ politica\&article $=024 \mathrm{n} 1 \mathrm{pol}$

Nick, T., Peck, J. y Brenner, N. (2009). Urbanismo neoliberal: la ciudad y el imperio de los mercados. Temas sociales (66), 2-12.

OCDE e Infonavit. (2015). Estudios de politicas urbanas de la OCDE: México. Transformaciones de la politica urbana y financiamiento de la vivienda. Recuperado de http://www.oecd.org/gov/sintesis-del-estudio-mexico.pdf
Paré, L. (2010). La relación campo-ciudad: elementos para la agenda en común. Alasru, 5. Recuperado de http://www.alasru.org/wp-content/uploads/2011/06/ALASRU2010Revista.pdf

Pina, A. (2013). Vivienda social en la Zona Metropolitana de Guadalajara. Geocalli. Cuadernos de Geografia, 14(27). Recuperado de http://www.publicaciones.cucsh.udg.mx/ppe$\mathrm{riod} /$ geocalli/volumenes/geo $27 . \mathrm{htm}$

Puebla, C. (2002). Del intervencionismo estatal a las estrategias facilitadores: cambios en la politica de vivienda en México. Ciudad de México: El Colegio de México.

Ruiz, A. (2013). Nuevas oportunidades en el sector vivienda. Ciudad de México: KPMG.

Salinas, A. (2009). El Estado en el proceso de acumulación por desposesión en el municipio de Chalco, estado de México Cuadernos de Geografia: Revista Colombiana de Geografia (18). DOI: 10.15446/rcdg Sánchez Corral, J. (2012). La vivienda "social" en México. Ciudad de México: JSa.

Sánchez Peña, L. (2012). Cambios en la segregación residencial socioeconómica en México. Revista Internacional de Estadistica y Geografia, 3(2). Recuperado de http://www.inegi.org.mx/ RDE/RDE_06/RDE_06_Art7.html

Schteingart, M. (1979). Sector inmobiliario capitalista y formas de apropiación del suelo urbano: el caso de México. Demografía y economía, 13(4), 449-466.

Torres, R. (2006). La producción social de vivienda en México. Su importancia nacional y su impacto en la economía de los hogares pobres. Ciudad de México: Estudios Metropolitanos, Conafovi, Conacyt, Coalición Hábitat México.

Warman, A. (1996). La reforma al artículo 27 constitucional. Recuperado de http://www.pa. gob.mx/publica/pa070203.htm 